\title{
Diamond exploration and prospectivity of Western Australia
}

\author{
M. T. Hutchison ${ }^{1,2}$ \\ ${ }^{1}$ Geological Survey of Western Australia, Perth,WA, Australia, mark.hutchison@dmp.wa.gov.au \\ ${ }^{2}$ Trigon GeoServices Ltd., Las Vegas, NV, United States, mth@trigon-gs.com
}

\section{Introduction}

Western Australia (WA) hosts $696000 \mathrm{~km}^{2}$ of exposed, onshore, exclusively Archean rocks and 439 $000 \mathrm{~km}^{2}$ of Paleoproterozoic rocks. In total, pre-1.6 Ga rocks comprise around $45 \%$ of the onshore area of the State, constituting the West Australian Craton (WAC; Yilgarn and the Pilbara Cratons) and the western part of the North Australian Craton (NAC). Seimic tomography demonstrates that considerable remaining portions of the State are also underlain by thick mantle lithosphere (Kennett et al., 2013), hosting the conditions under which diamonds form. Subsequently, most of the State is prospective for diamonds and numerous diamondiferous lamproite and kimberlite fields are known. Emplacement of diamond-bearing rocks spans much of geological time, from the c. 1868 Ma Brockman Creek kimberlite in the Pilbara (White, 2000) to the c. $17 \mathrm{Ma}$ Walgidee Hills lamproite, Noonkanbah field, West Kimberley (Phillips et al, 2012). According to Kimberley Process statistics, Australia is estimated to have produced approximately $11 \%$ of global rough diamond production by weight in 2015 , ranking it fourth in the world after the Russian Federation, Botswana and the Democratic Republic of Congo. These production figures are accounted for by two mines, both in WA. However, due to the closure of the Ellendale mine in 2015, responsible for a large proportion of the world's fancy yellow production, only one currently producing mine remains in Australia (at the AK1 olivine lamproite at Argyle, NAC). In order to assess the effectiveness of prior exploration and draw attention to under-explored prospective areas, a thorough compilation and interpretation of WA diamond exploration data has been conducted.

\section{Methodology}

Despite its position in world-wide diamond production, the size, terrain, infrastructure and climate of Western Australia has resulted in many areas being underexplored. Some 68\% of the State's onshore areas lie over $20 \mathrm{~km}$ from a known diamond exploration sample site. Yet continuous diamond exploration since the 1970s has resulted in abundant data, including 4200 company reports citing diamond as a commodity of interest. In construction of a Diamond Exploration Database (DED) focus has been applied on the primary method of exploration, that is, physical sampling. The DED for Western Australia incorporates the locations of over 88000 diamond exploration samples, the overwhelming majority ( $\sim 90 \%$ ) being taken for separation of diamonds or other minerals indicating diamond potential. Associated with these samples are over 30000 good quality chemical analyses of mineral separate grains. Furthermore, locations of 523 discrete in-situ bodies which in principal have a diamond potential (kimberlites, lamproites, ultramafic lamprophyres and carbonatites), have been compiled, with 114 confirmed to be diamondiferous. As a companion to the in-situ occurrences, 127 emplacement age determinations from 63 bodies are compiled with detailed geochronological information.

To assess prospectivity, the State has been subdivided into 67 onshore tectonic units in 4 geographic areas. The extent and results of sampling, in conjunction with the age of surface rocks relative to ages of diamond-propsective rocks, and the underlying mantle structure have been analysed in order to produce a prospectivity map. Methodology follows that of Hutchison (2013) for the Northern Territory (NT). The resulting map presents a 13-level ranking of attractiveness for future diamond exploration.

\section{Mineral Sampling Results}

Indicator distributions and sampling methodologies show that programs recovering $0.3-0.4 \mathrm{~mm}$ grains from high-energy trap sites are most successful. Diamond occurred in $3.5 \%$ of indicator mineral samples, whereas non-diamond indicators were identified by visual inspection in $28 \%$ of samples. The large majority are spinels, relatively durable in the harsh Western Australian weathering environment. 
In addition to chromite, diopside, garnet, ilmenite, monticellite, orthopyroxene, olivine, perovskite, phlogopite, pseudobrookite and tourmaline with indicator chemistries have all been recovered. False positives occur amongst grains which are identified only visually. However, $80 \%$ (over 25000 ) of goodquality mineral compositional analyses are classified as genuine indicators. Ninety-one percent of indicator spinels are mantle-derived chromites and clinopyroxenes largely show garnet peridotite affinity. Twenty five per cent of peridotitic garnets are G10s (following Grütter et al., 2004). Amongst ilmenites, 93\% with indicator chemistry fall within the kimberlite field (following Wyatt et al. 2004).

Figure 1: Diamond prospectivity of Western Australia. Geological subdivisions are ranked for prospectivity in the context of mantle structure, the age of surface rocks, the extent of sample coverage and recovery of visuallydetermined indicators. Ranking follows the key, with 1 being the most prospective area. In-situ bodies are shown by stars: green - kimberlite; yellow - lamproite; red ultramafic lamprophyre / carbonatite. Sample sites are shown by small black dots with a $20 \mathrm{~km}$ radius indicating explored areas. Larger circles indicate sites of recovery of visuallydetermined indicator minerals with colours in the key. Principal roads are marked in red. Diamond and chromite distinguish themselves as the most robust and hence commonly-recovered indicator minerals. Much of WA is under-explored with prospective areas in the NAC and particularly the WAC.

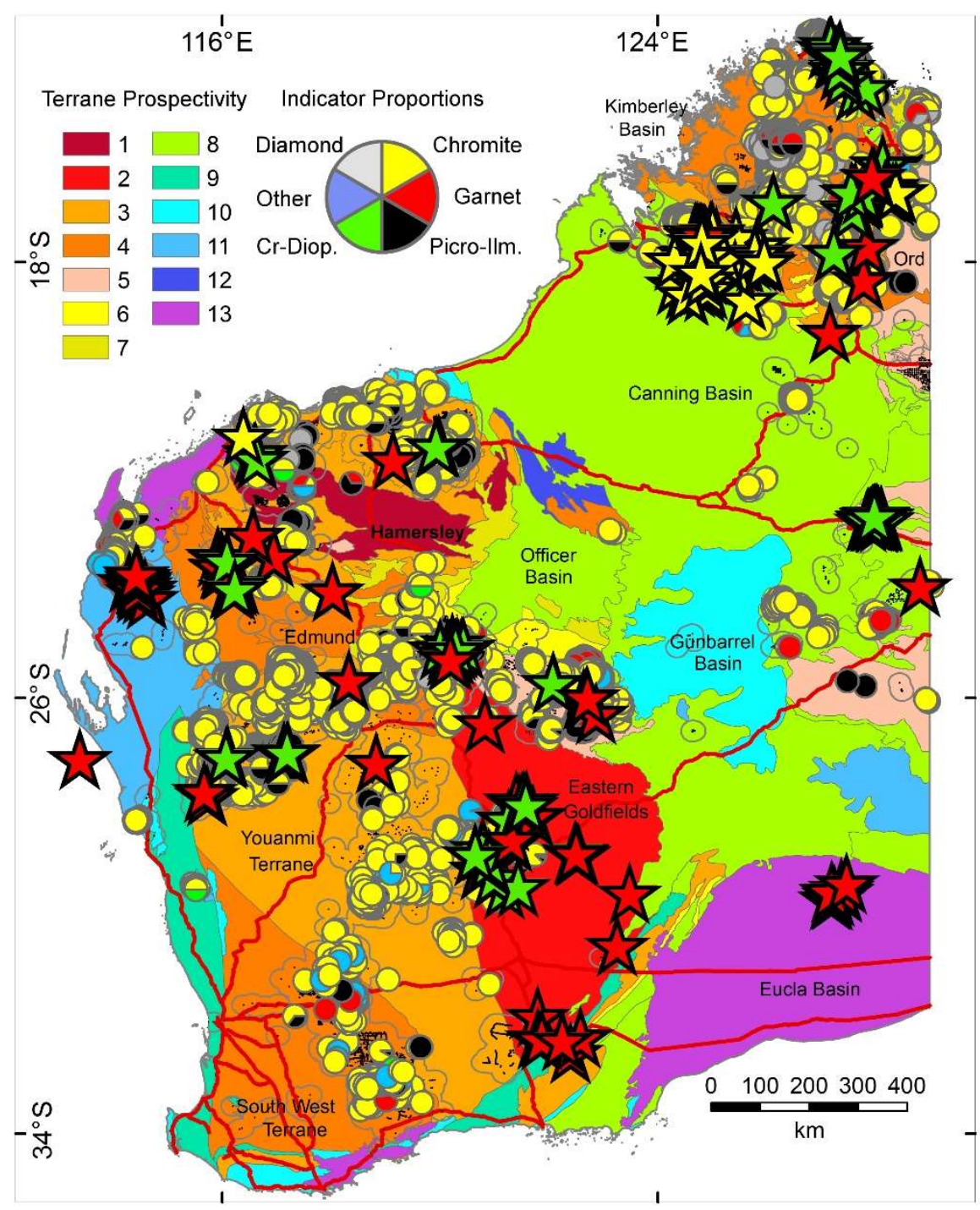

Yellow and pink diamonds contribute $5 \%$ and $1 \%$ of the State-wide regional sampling populations; colours reflected in production from the Argyle and Ellendale mines. Of original growth forms octahedral forms are most abundant (45\%), in contrast to the NT where cubes dominate (Hutchison, 2013). This suggests relatively higher formation temperature and mature, deeper and more prospective diamond growth settings than farther east-northeast in the NT. However, $41 \%$ are dodecahedral or tetrahexahedral and 53\% of octahedral stones show surface etching and resorption. Considerable proportions of diamonds have been distressed, either at formation depths or during emplacement, consistent with the chemical incompatibility between diamond and some WA diamond host rocks, particularly leucite lamproites.

\section{Geographic Variations and Regional Prospectivity Ranking}

Indicator mineral occurrences and in-situ bodies with diamond potential (Figure 1) largely occupy the 
north (NAC) and west (WAC) of the State. These areas correspond to thick mantle lithosphere (Kennett et al., 2013) establishing the conditions for diamond growth. Clusters in Figure 1 particularly correlate with areas of significant changes in mantle thickness reflecting structures favourable for diamond emplacement. Similar features also extend into under-sampled areas, the most notable being the farwest Kimberley, the extension of thickened lithosphere south of the Kimberley into the Proterozoic basement of the Arunta, the boundary between the Capricorn Orogen and the Archean to Proterozoic Hamersley Basin, and the east and central-west Yilgarn in the WAC.

With the exception of thinner mantle under the Pilbara, the cratonic regions of WA and the NT are underlain by particularly thick mantle lithosphere (220-240 km; Kennett et al., 2013). However, geothermobarometry from Merlin kimberlites in the NT (Hutchison, 2013) shows that some mantle minerals derive from considerably shallower depths $(\sim 160 \mathrm{~km})$. The spectra of indicator chemistry throughout WA demonstrates the same effect, that mantle material has been derived from depths not necessarily at the base of the lithosphere. Garnets show clear geographic subdivision with the lherzolitic trend being more Ca-depleted in WAC samples compared to the NAC. Although the main trend is not as prominantly bordering the G10 field as from the Merlin field of the eastern NAC in the Northern Territory (NT; Hutchison, 2013), WAC samples show a much broader scatter into strongly diamondprospective G10 and G10D compositions. For WA ilmenites, NAC samples extend the western NTborder samples further into Mg-enriched compositions consistent with kimberlites. However, consistent with findings for garnets, ilmenites from the WAC (particularly the Hamersley Basin and Eastern Goldfields) show the most diamond-prospective trend. As the prospectivity model assesses mineralogy in addition to regional mantle structure, variations in source depth are accounted for. Figure 1 shows the results of ranking terranes with areas colour-coded according to prospectivity. The NAC, location of WA's diamond mines, scores well. However, partly because of under-sampling combined with good indicator recovery, results point to parts of the WAC being more prospective. Most notable are the Hamersley Basin, Eastern Goldfields Superterrane and the Goodin Inlier of the Yilgarn Craton.

\section{Conclusions}

Despite prolific diamond exploration, Western Australia is considerably under-explored and the ageing Argyle mine and recent closure of operations at Ellendale warrant a re-evaluation of diamond potential. Indicator mineral chemistries reflect mantle sources with respectable diamond tenor, consistent with diamond and visually-determined indicator recovery, known diamondiferous source rocks and mining in parts of the State. However, analysis of exploration data also draws attention to under-explored areas particularly in the WAC. As kimberlite and lamproite emplacements span $2500 \mathrm{Ma}$, there are significant opportunities for diamond-affinity rocks being present near surface even within the large, under-explored sedimentary basins overlying thick mantle lithosphere evident through much of the State. Results of prospectivity analysis make a compelling case for renewed diamond exploration.

\section{References}

Grütter HS, Gurney JJ, Menzies AH, Winter F (2004) An updated classification scheme for mantlederived garnet, for use by diamond explorers. Lithos 77: 841-857

Hutchison MT (2013) Diamond Exploration and Regional Prospectivity of the Northern Territory of Australia. In: Pearson DG et al. (eds) Proceedings of the 10th International Kimberlite Conference, Volume 2, Special Issue of the Journal of the Geological Society of India, pp 257-280

Kennett BLN, Fichtner A, Fishwick S, Yoshizawa K (2013) Australian Seismological Refence Model (AuSREM): mantle component. Geophysical Journal International 192: 871-887

Phillips D, Clarke W, Jaques AL (2012) New ${ }^{40} \mathrm{Ar} /{ }^{39} \mathrm{Ar}$ ages for the West Kimberley lamproites and implications for Australian plate geodynamics. 10 IKC Ext. Abs. Bangalore, India: 10IKC-104

White B (2000) The geochronology and thermochronology of the Brockman Creek 01, Melita and Melita 02 kimberlites, Western Australia. Unpubl. Hons. Res. Rep., Univ. Melbourne

Wyatt BA, Baumgartner M, Anckar E, Grütter H (2004) Compositional classification of "kimberlitic" and "non-kimberlitic" ilmenite. Lithos 77: 819-840 